\title{
Plagiarism : j’accuse...!
}

\author{
Luc De Smet
}

From UZ Leuven, Belgium

This could be a good title for this editorial, if it hadn't already been used in 1898 by Emile Zola. This is, however, what this editorial is all about.

Recently we were confronted with the disgusting phenomenon of plagiarism.

J. Vles and colleagues send a manuscript to the editorial board of this journal (The majority of conversion total hip arthroplasties can be considered as primary replacement - a matched cohort study by Georges Vles, Luke Simmonds, Mark Roussot, Andrea Volpin, Fares Haddad, Sujith Konan) which was reviewed by an expert and accepted for publication as soon as possible.

To their (and our surprise) this paper was published (with the same title and content) by other authors (Soufiane Aharram, Mounir Yahyaoui, Jawad Amghar, Abdelkarim Daoudi, Omar Agoumi) in the European journal of Medical Research.

The webmaster conducted a search and found that there was indeed a break-in into the digital archives of the Acta. Several papers were downloaded and some were already published in other journals by the same group of authors.

An article "Gram stain microscopy in septic arthritis", rejected by the Acta was published by the same group in "International Medical Journal".

Likewise "Comparative Evaluation of Manual and Automated Intra-Articular Irrigation Systems ...", by Olcay Güler.
The base of medical publishing is to share knowledge with the community in order to improve patient care. There is nothing wrong with checking data, modifying techniques or even in repeating the same research. However using someone else's data, ideas or techniques and claiming these as yours is generally called plagiarism. This however is worse: this is plain theft!

In an era in which hacking seems to become a popular sport, we are aware that we all should protect our data, our identity and privacy, but how far has one to go: This is a small, local orthopaedic journal, it does not contain the launching codes for nuclear missiles.

We, the editorial board, work with mutual confidence: we send papers to reviewers and trust that they do the review in all honesty. We cannot explore the history of each manuscript presented to us nor can we do a follow-up of each accepted or rejected papers.

The webmaster has found the breach and undertaken action to prevent such shameless theft in the future.

The specific theft mentioned above will not be left unanswered; legal procedures have been started, journals have been warned.

Luc De Smet, MD, PhD

UZ Leuven

Correspondence : Luc De Smet, UZ, Leuven, Belgium.

Email : lucdesmet24@hotmail.be

- 2021, Acta Orthopædica Belgica. 